\title{
The Use and Misuse of Mobile Phones in the Maternity Ward-A Threat to Patient Safety?
}

\author{
Bente Dahl1, Sandra Åkenes-Carlsen ${ }^{1,2}$, Elisabeth Severinsson ${ }^{1}$ \\ ${ }^{1}$ Centre for Women's, Family \& Child Health, Department of Nursing and Health Sciences, Faculty of Health and Social Sciences, \\ University College of Southeast Norway, Kongsberg, Norway \\ ${ }^{2}$ Obstetric Unit, Department of Obstetrics/Gynecology and Pediatrics, Østfold Hospital Trust, Grålum, Norway \\ Email: bente.dahl@usn.no
}

How to cite this paper: Dahl, B., ÅkenesCarlsen, S. and Severinsson, E. (2017) The Use and Misuse of Mobile Phones in the Maternity Ward-A Threat to Patient Safety? Open Journal of Nursing, 7, 707-719. https://doi.org/10.4236/ojn.2017.76053

Received: May 19, 2017

Accepted: June 25, 2017

Published: June 28, 2017

Copyright (c) 2017 by authors and Scientific Research Publishing Inc. This work is licensed under the Creative Commons Attribution International License (CC BY 4.0).

http://creativecommons.org/licenses/by/4.0/

(c) (i) Open Access

\begin{abstract}
An important task for the midwife is following up mother-child interaction to facilitate mother-infant attachment. The aim of this study was to explore midwives' perceptions of parents' use of mobile phones in the maternity ward. The research question was: Is the use of mobile phones in the maternity ward a threat to patient safety? Two focus group interviews exploring midwives' perceptions $(\mathrm{n}=10)$ of parent' use of mobile phones during and after the birth were conducted in January 2016. Systematic text condensation was used to analyse the data, revealing three themes pertaining to safety concerns: Interrupted communication due to parents' excessive use of mobile phones during labour and postnatally, Unsafe care caused by lack of attention to the newborn baby's signals as a result of being disturbed by the mobile phone and Unsafe care because of parents interrupting their conversation with the midwife by answering the mobile, acting in a disrespectful manner and failing to pay attention. The midwives' descriptions of parents' use of mobile phones in the maternity ward included reflections on mobile phone usage as a permanent phenomenon. They were concerned that parents' use of mobile phones in the maternity ward could negatively affect the attachment process and considered that it interrupted their work. In conclusion, there is a need for increased awareness of parents' use of mobile phones in the maternity ward. Further research is required to gain greater insight into the consequences of mobile phone use in order to promote patient safety by ensuring effective communication between parents and midwives. In addition, research is needed to explore the safety discourse, clinical risks and/or health problems involved in the development of infant-parent attachment in newborn babies.
\end{abstract}

\section{Keywords}

Communication, Focus Group Interviews, Infant-Parent Attachment, Midwife, Maternity Care, Mobile Phone, Patient Safety 


\section{Introduction}

The consequences of using mobile phones may or may not influence the professional relationship between midwives and childbearing women and thus the quality of maternity care. The mobile phone (cellular phone) was developed in the 1950s, but became accessible to and popular with the general population in Norway in the 1990s. Today, seven out of every ten persons in Norway possess a Smartphone, thus the Norwegian population is one of the most enthusiastic mobile phone using populations in Europe [1]. Research concerning the use of mobile phones in maternity care involves the use of Smartphone Apps as well as social media platforms. A Cochrane review described that pregnant women who received supportive and informative text messages experienced higher satisfaction, greater confidence and lower anxiety levels in the antenatal period than women who did not receive such messages [2]. An American survey examining new parents' use of Facebook in their transition to parenthood reported that mothers' use of Facebook increased during the transition and that their frequent Facebook visits were associated with higher levels of parenting stress. Fathers, on the other hand, reported better parental adjustment when connecting with their Facebook friends [3]. The use of apps and social media platforms in maternity care appears to have the potential to influence pregnancy, motherhood and parenting practice [4]. Consequently, Tripp et al. [5], argue that healthcare professionals should be aware of new information delivered via Smartphones, as these are widely used by women of childbearing age. However, one of the consequences of having access to one's mobile phone is that a vast number of young people check their phones frequently in order not to miss information shared on social media. This exaggerated use is referred to as "fear of missing out" (FoMo) on important and exciting events [6] [7].

The use of mobile phones related to social media in the maternity ward is a relatively new phenomenon and has been frequently discussed in the Norwegian media. Midwives are concerned that the use of mobile phones during and after the birth represents a new challenge to the infant-parent attachment process, raising the question of whether babies have to compete with the Internet and social media to get their parents' attention [8]. They are also concerned about mothers' abilities to read their babies' signals in view of the fact that they focus on their mobile phones rather than on their babies while breastfeeding [9] [10] .

Research concerning healthcare professionals' perceptions of mobile phone use in the maternity care context is scarce, despite the fact that communication failure constitutes a threat to patient safety [11]. Conflicts between patients and healthcare professionals due to lack of communication when problems arise have been reported, although pregnant women were found to be insistent and vehement when alerting midwives about safety issues that they believed to be urgent [12]. Five patient risk domains have been reported: organization, communication, patient-related risk factors, clinical management and midwifery care outcomes [13]. 
Aim

As failure to communicate effectively is the most common cause of medical errors and therefore a threat to patient safety [14], we decided to conduct a study to examine aspects of communication in the maternity ward including midwives' perceptions of parents' use of mobile phones in order to answer the research question: Is the use of mobile phones in the maternity ward a threat to patient safety?

\section{Methods}

\subsection{Design}

We employed a qualitative inductive research approach to illuminate midwives' perceptions of the use of mobile phones in the maternity ward [15] [16]. This approach results in a narrative summary that synthesizes participant information, thereby creating a description of human experiences. The "theoretical lens" is based on the World Health Organisation (WHO) patient safety recommendations [17]. The WHO defines patient safety practices as processes or structures that reduce the probability of adverse events caused by exposure to the healthcare system across a range of diseases and procedures [18].

\subsection{Data Collection and Participants}

Participants were recruited from a large hospital in Southeast Norway in 2016. A Professional Development midwife employed at the maternity ward informed all midwives about the study and a detailed information sheet was handed out to potential participants before the interviews took place. We included authorized midwives who were able to understand and speak Norwegian fluently. Twelve midwives who were interested in participating in the study contacted the second author by email, although two later withdrew due to their heavy workload. The remaining ten midwives were divided into two focus groups consisting of four and six members.

The two focus group interviews were conducted in the participants' work place and lasted for 50 and 55 minutes [19]. An interview guide containing the following four questions was employed; 1) Can you describe your experiences of new parents' use of mobile phones in the maternity ward? 2) Can you describe any examples where parents' use of mobile phones may have influenced the infant-parent attachment process? 3) Should midwives draw attention to the importance of infant-parent attachment and 4) How can midwives facilitate the attachment process in a digitalized society? The second author acted as moderator and a colleague as secretary. The midwives were encouraged to narrate freely but were informed before the interviews started that the moderator would interrupt if necessary. The interviews were audiotaped and field notes taken.

\subsection{Data Analysis}

The interviews were transcribed verbatim and systematic text condensation (STC) was used to analyse the data [20]. STC is a four step strategy for thematic 
cross case analysis inspired by Giorgi's phenomenological method. In the first step, the interviews were read to gain an overall impression and preliminary themes were noted. The second step concerned the coding process, during which the transcripts were read line-by-line and meaning units, i.e., parts of the text that could illuminate the research question, were identified, classified and labelled, after which related meaning units were organized into groups and coded.

In the third step, the content of each group was sorted into subgroups and condensed. Finally, an analytical text based on the condensates emerged, including quotations to elucidate the findings.

\subsection{Ethical Considerations}

The study was conducted in accordance with the Declaration of Helsinki [21]. Before the interview started, the participants received oral information about the study and were asked to sign a declaration of consent. They were informed that participation was voluntary and that they could withdraw from the study at any time without having to give a reason. Approval for the study was granted by the Norwegian Social Science Data Service (NSD; 45,362) and the approval was assessed by the Regional Committee for Medical Research (2015/2064A).

\section{Results}

Twelve midwives expressed an interest in participating in the study. They worked in different hospital wards, ranged in age from 28 to 50 years, as well as having varying seniority and work experience within maternity care $(1-20)$.

The analysis revealed three themes; 1) Interrupted communication due to parents' excessive use of mobile phones during labour and postnatally, 2) Unsafe care caused by lack of attention to the newborn baby's signals as a result of being disturbed by the mobile phone and 3) Unsafe care because of parents interrupting their conversation with the midwife by answering the mobile, acting in a disrespectful manner and failing to pay attention to the midwife.

\subsection{Interrupted Communication Due to Parents' Excessive Use of Mobile Phones during Labour and Postnatally}

In the first theme, the midwives expressed concern that mobile phone use related to social media reduces parents' ability to focus on the labour and the newborn baby, but patient autonomy prevents them from restricting the use of mobile phones.

\subsubsection{Mobile Phones Are Here to Stay}

Despite their concerns, the midwives agreed that mobile phones are here to stay. They stated that while some parents did not use the mobile phone during labour, and only employed it to inform their family about the birth several hours after the baby was born, others used it continuously to share information about the ongoing situation and update family and friends. The midwives believed it was essential for young parents to share information on social media. However, one midwife reflected on the amount of time mothers in the post-natal ward seem to 
spend checking the number of likes on their Facebook postings, while others were concerned about the loss of control associated with spreading the news by means of social media. Another midwife was puzzled when she found friends accompanying a labouring couple sitting outside the birthing room and watching the ongoing birth via Skype. The midwives believed that young people are more or less "attached" to their mobile phones, and understood that their social lives were dependent upon this device. According to an experienced midwife:

Young people depend on their mobile phone, it seems to be "glued" to their bodies. My generation are able to put it away... we can enjoy that. I don't think young people enjoy that, it is frustrating for them not to have their mobile phone close at hand and I wonder if the baby will be able to capture the attention that they devote to their mobile. I don't know. How extreme is their love affair with that gadget? (Focus group 1).

\subsubsection{Mobile Phones Use Results in a Change of Focus}

All the midwives had personal experience of parents using mobile phones during labour and postnatally. It often started before the baby was born, with parents updating family and friends about the progression of labour, frequently by means of social media such as Facebook, Twitter or Instagram. They perceived this as disturbing, because instead of concentrating on the labour process as a team, the parents were occupied updating family and friends. Although labouring women took an active role in updating family and friends, the prospective fathers seemed even more concerned with information sharing and sometimes handled two mobile phones simultaneously. The midwives perceived fathers' use of mobile phones as a possibility for them to escape from the situation for a few minutes, which they understood. However, unfortunate situations sometimes occurred, particularly when fathers were so occupied with their mobile phones that they had no time to care for their partners. According to one of the midwives, some situations were difficult to forget:

I entered the birthing room; the woman was eight centimetres dilated. She was lying on her side, totally distressed and groaning. The father was watching a skiing competition on his mobile phone. "Just a moment", he said, which I found a bit peculiar (Focus group 2).

\subsubsection{Mobile Phones Use Concerns Patient Autonomy}

Some midwives asked the parents to put their mobile phones away when they entered the birthing room, arguing that it was their job to provide the parents with important information. Others found this difficult and said nothing. Several argued that they gained an overall impression of the parents and interrupted when they considered it necessary to intervene, e.g., if they noticed that the parents spent more time with their mobile phones than with their baby. However, they found it peculiar that they had to inform adults to put away their phones in order to have a conversation. They talked about the "old days" when parents had to ask permission to use the hospital telephone and stated that although they did not wish to interfere with the parents' private lives, they would like to be able to 
communicate to the parents that they should cherish the first days after the birth. However, they sometimes found it difficult to separate patients' autonomy and their professional knowledge. According to one of the midwives:

I believe that sometimes we are a little afraid to let them know that... we are afraid of offending them or barging into their private lives. Maybe we should be more specific, because this is an important time in their lives (Focus group 1).

\subsection{Unsafe Care Caused by Lack of Attention to the Newborn Baby's Signals as a Results of Being Disturbed by the Mobile Phone}

The second theme concerns the challenges related to parents' ability to understand the newborn baby's signals. Furthermore, midwives feared that use of mobile phones could hinder the initiation of breastfeeding and wondered if mobile phones might have a negative influence on the baby's health.

\subsubsection{Mobile Phone Use Reduces Parents' Ability to Notice the Baby's Signals}

The midwives agreed that extensive use of mobile phones was likely to disturb the infant - parent attachment process, and felt sad when they entered a room and found the newborn in its cot while the mother was lying in bed with her mobile phone or laptop. They argued that parents who spend a great deal of time using their mobile phones were less attentive to their baby and risked missing her/his natural signals, such as smacking the lips and sticking out the tongue out when hungry. It could also concern signals related to a change in health status, such as low blood sugar or increased temperature. Overall, they considered that parents today are less attentive to their babies and lack knowledge about the attachment process. They argued that it is easy for young parents to get to know their mobile phones, but getting to know a newborn baby is more demanding. According to one midwife:

The baby needs to have its signals reciprocated, to see the mother smile, to have eye contact and see different facial expressions. I do not think that parents know how competent the newborn baby really is. They should look at their baby instead of their mobile phones (Focus group 1).

\subsubsection{Mobile Phone Use Disturbs the Breastfeeding Process}

The midwives reported that mothers' focus on the mobile phone sometimes disturbed the breastfeeding process. They perceived that mothers lacked understanding about the importance of ensuring a good start to breastfeeding their babies and thought it was sad that they had to request the mothers to put away their mobile phones when breastfeeding. They reflected on the mothers' lack of knowledge and discussed whether it would be a good idea to design breastfeeding and attachment apps because young mothers and families often googled the Internet to find information on various topics. They believed that it might be a good idea to meet the women or families on their own terms and at the same time provide them with correct information. 
They discussed what a future postnatal support group would look like:

It would be interesting to be a fly on the wall in future postnatal support groups (using body language to demonstrate how mothers sit looking down at their mobile phones). I think that we have a duty to continue the fight, but we have to find other ways... like an app or something. We are up against a tough crowd (Focus group 1).

\subsubsection{Mobile Phone Use May Have a Negative Influence on the Baby's Health}

The midwives were concerned that the use of mobile phones could have a negative impact on the baby's health. They were particularly worried about radiation, as they had noticed that parents often put their mobile phones into the baby's cot, close to her/his head. In addition, they believed that light, shrill sounds, and vibration might disturb the baby. While they were aware that this concern was not backed by evidence-based knowledge, they argued that as Norwegian health authorities had recommended that adults should avoid sleeping with their mobile phones in their bed, parents should also avoid putting their mobile phones next to the baby's head. One midwife expressed her concern as follows:

Well, you have radiation, you have vibration and suddenly there is a shrill sound. No... I do not know... it is not evidence-based, but it feels as if it is not good for the newborn baby (Focus group 2).

\subsection{Unsafe Care because of Parents Interrupting Their Conversation with the Midwife by Answering the Mobile, Acting in a Disrespectful Manner and failing to Pay Attention}

The third theme concerns midwives' experiences of being disturbed in their clinical practice during labour as well as postnatally.

\subsubsection{Mobile Phone Use Disturbs Midwives' Work in the Labour Ward}

The midwives stated that parents' use of mobile phones during labour hindered their work.

Furthermore, at times they found the use of mobile phones disrespectful and were uncomfortable with photos being taken without their permission. They described the sounds and flashing from the mobile phone as surrounding both the mothers and themselves, adding that the minutes after the baby is delivered are critical and should not be disturbed. The women are often in a lithotomy position with their legs in stirrups, waiting to deliver the placenta while the midwife examines them. At this stage, there is a risk of bleeding, making it is essential that midwives are allowed to perform their work without being disturbed.

One of the midwives described feeling overrun by an overeager father taking photos while she was waiting to deliver the placenta:

The parents were on the phone continuously. I had to raise my voice and say "Turn off your phones right now?". Having to ask them to switch off their phones was the most extreme case I have ever encountered. Strictly speaking, it is none of my business at all, but it disturbed the birth (Focus group 1). 


\subsubsection{Mobile Phone Use Disturbs Midwives' Work in the Postnatal Ward}

The midwives also described being obstructed in their work after the birth. They experienced that the parents were too preoccupied with their mobile phones to listen to the information that the midwives provided. They stated that in the course of a conversation the parents would abruptly stop talking in order to answer the telephone, which they considered both frustrating and disrespectful. They argued that parents would miss out on important information as a result. One midwife described that after several attempts to give the parents important information, she ended up documenting in the mother's records that the woman was too busy with the mobile phone to talk to her. Another midwife stated that she had stopped saying she would come back later:

You come in to give them information and they are busy using their mobile phones. It provokes me. Previously I said that I would come back later, but I have stopped saying that. Instead, I say that they have to contact me if they want information (Focus group 2).

\section{Discussion}

The findings in this study describe challenging situations related to midwives' perceptions of parents' use of mobile phones in the maternity ward. Below, we will discuss the findings from a patient safety perspective, focusing on various aspects of communication.

The importance of good communication in antenatal care is well recognized and found to have a positive effect on patient outcomes such as anxiety, pain control and understanding of information [22]. According to Hunter et al. [23], the quality of communication and relationships is interrelated, and effective communication is essential for safe practice. Relationships are therefore important for the "soft side of care" as well as for clinical safety. Accordingly, the authors argue, poor communication between professionals and clients can be regarded as an aspect of sub-standard care. According to Raine et al., [22], a shift towards a partnership model of care will result in greater access to information, while client involvement, such as shared decision-making and self-management, is essential in order to ensure safety and improve the relationship between maternity care staff and clients [24]. In this study, midwives reported that their clients spend a great deal of time on the Internet and on social media both communicating and seeking information, support and advice. They consider that this had led to a "change of focus" during birth, with parents being too occupied with their phones to participate in the here and now. In these situations they find it difficult to establish a good relationship with the parents and to help them to focus on the birthing process. However, according to Currie and Richens [25], midwives may perceive a loss of power and control in the face of having to deal with an increasingly assertive and articulate client population who know about choice. According to Johnson [4], first-time motherhood (and seemingly first time-parenthood) in a digitalized world involves parents' use of a variety of new devices that are likely to influence and change the way we under- 
stand and practice maternity care and motherhood. In our study, midwives' stated that they are uncomfortable with the changes taking place, but have to accept them due to patient autonomy.

The midwives were concerned that parents' mobile phone use also resulted in a change of focus after the birth, disturbing the attachment process between the newborn child and her/his parents. They argued that in order to prevent the baby from being under stimulated, the parents must pay attention to her/his. They stated that a newborn baby exhibits a variety of cues, such as lip smacking when hungry, and parents must learn how to interpret them. Thus, if parents look at their mobile phones rather than at the face of their baby, they will miss out on important information enabling them to understand the baby's wellbeing. According to Stern [26] (p. 63), much parent-infant interaction is played out at a microevent level. He states that the "nonverbal behaviours that make up a great part of this relationship are not communications about, nor comments upon, nor interpretations of the relationship; they are the relationship". Midwives do not refer to theoretical knowledge of the attachment process when they describing their concern, but argue that it is important for parents to be present and attentive to the baby's signals, as well as questioning whether young parents have sufficient knowledge of the attachment process. Thus, they reflect on the possibility of developing apps to provide young parents with good quality information about breastfeeding and attachment.

Studies have described the relationship between a labouring woman and her caregiver as fundamental to the woman's experience of childbirth [27] [28]. In this regard, trust is essential. According to Rørtveit et al. [29], there are four key features of trust: what it is, why it matters, on what it is based, and the danger of trust. However, facilitating and nurturing trust are related to communication, thus communication skills are important for healthcare providers and an integral component of safety culture [30]. Midwives have an opportunity to provide close and tailored care for women by optimizing the normal childbirth process and post-partum period [31]. Thus, when midwives are obstructed and prevented from "working with" the woman and her family to establish a trusting relationship and provide patient-centred care they may find it challenging. There were several situations in the present study where clients' excessive use of mobile phones restricted the midwives' ability to share important information and to build a trusting relationship with them, resulting in frustration about being unable to provide the mothers with essential, knowledge-based information. Furthermore, they described birthing situations where parents' excessive use of mobile phones disturbed their job performance, which they considered both challenging and a threat to patient safety as they risked missing out on important details concerning the health of mother and child. It has been reported that mutuality in the woman-midwife relationship is necessary for good care [32] [33] and that for the midwife, a feeling of being needed can be perceived as a recognition of her role [34] [35]. However, our study also demonstrates that midwives' perceptions of clients' need for support are based on their own ideas 
of the purpose of care rather than clients' perceived care needs. Further studies are required to elucidate this discrepancy in order to enhance communication and patient safety in the maternity care context.

\section{Limitations}

According to Malterud [36], internal validity concerns whether the study has investigated what it was intended to investigate and whether the methods employed were appropriate. The use of focus groups and an interview guide listing a limited number of fixed questions allowed the midwives in this study to reflect on their experiences, thus providing the authors with sufficient empirical data to broadly elucidate the research question. Two authors conducted the structural analysis and achieved consensus on the interpretation, while the third author validated the themes. However, we are aware that other researchers might have identified different themes or interpreted the findings differently.

To enhance external validity, it is necessary to consider whether it is possible to generalize the findings beyond the setting in which they were generated [36]. Our convenience sample consisted of ten midwives of different ages and seniority employed in various wards, thus although it was small, it was rich. However, the sample was recruited from one institution, which may have influenced the external validity. The study would have benefitted from including participants from Non-Western countries and from several institutions. The authors have different healthcare backgrounds (midwives and a psychiatric nurse) and experience within maternity care, providing varied perspectives and a solid knowledge base. Furthermore, they share a common interest in midwifery and the technological innovations utilized within the maternity care context.

\section{Conclusion}

Mobile phones have changed our society as well as our way of communicating, and easy access to the Internet and social media has become a part of our daily lives. The present study demonstrates that midwives are concerned about the situation, in particular the way in which parents' use of mobile phone use may affect the infant-parent interaction and pose a threat to patient safety. They argue that there is a need for increased awareness about the use of mobile phones in the maternity ward. Additional research is required to gain further insight into the consequences of mobile phone use in order to promote patient safety and ensure effective communication between parents and midwives.

\section{Funding Statement}

We acknowledge that the study was supported by a grant from the Centre for Women's, Family \& Child Health, Faculty of Nursing and Health Sciences, University of Southeast Norway, Kongsberg, Norway.

\section{Authors Contributions}

B.D. and S.Å-C were responsible for study design. S.Å-C was responsible for the 
data collection and writing the initial manuscript. S.Å-C and B.D were responsible for data analysis. All authors contributed intellectually, proof read and approved the final manuscript. BD supervised the study.

\section{Acknowledgements}

The authors would like to thank the midwives who participated in the study. We would also like to thank Monique Federsel for proofreading the English language.

\section{References}

[1] Medienorge (2016) Andel som har Smarttelefon. Medienorge, Fakta om norske medier. (In Norwegian) http://www.medienorge.uib.no

[2] Vodopivec-Jamsek, V., de Jongh, T., Gurol-Urganci, I., Altun, R. and Car, J. (2012) Mobile Phone Messaging for Preventive Health Care. The Cochrane Database of Systematic Reviews, 12, CD007457. https://doi.org/10.1002/14651858.CD007457.pub2

[3] Bartholomew, M.K., Schoppe-Sullivan, S.J., Glassman, M., Kamp Dush, C.M. and Sullivan, J. (2012) New Parents' Facebook Use at the Transition to Parenthood. Family Relations, 61, 455-469. https://doi.org/10.1111/j.1741-3729.2012.00708.x

[4] Johnson, S.A. (2014) Maternal Devices, Social Media and the Self-Management of Pregnancy, Mothering and Child Health. Societies, 4, 330-350. https://doi.org/10.3390/soc4020330

[5] Tripp, N., Hainey, K., Liu, A., Poulton, A., Peek, M., Kim, J. and Nanan, R. (2014) An Emerging Model of Maternity Care: Smartphone, Midwife, Doctor? Women and Birth, 27, 64-67.

[6] Vaughn, J. and Mack, A.M. (2012) Fear of Missing Out (FOMO). Trend Reports. J. Walter Thompson Company, New York.

[7] Clayton, R.B., Leshner, G. and Almond, A. (2015) The Extended iSelf: The Impact of iPhone Separation on Cognition, Emotion, and Physiology. Journal of Computer-Mediated Communication, 20, 119-135. https://doi.org/10.1111/jcc4.12109

[8] Ystaas, S. and Hustad, K.V. (2015) Må Be Foreldrene Legge fra seg Mobilen på Fødestua. (In Norwegian)

[9] Langset, K.G. (2015) Vi ser Nybakte Mødre som Ikke får med seg Signaler på Sult. Aftenposten Nettavis. (In Norwegian) http://www.aftenposten.no

[10] Quist, C. and Ertesvåg, F. (2015) Mobilen Rammer Mammas Amming. (In Norwegian) http://www.vg.no

[11] Severinsson, E., Haruna, M., Rönnerhag, M. and Berggren, I. (2015) Patient Safety, Adverse Healthcare Events and Near-Misses in Obstetric Care-A Systematic Literature Review. Open Journal of Nursing, 15, 1110-1122.

https://doi.org/10.4236/ojn.2015.512118

[12] Rance, S., McCourt, C., Rayment, J., Mackintosh, N., Carter, W., Watson, K. and Sandall, J. (2013) Women's Safe Alerts in a Maternity Care: Is Speaking up Enough? BMJ Quality \& Safety, 1-8. https://doi.org/10.1136/bmjqs-2012-001295

[13] Martijn, L., Jacobs, A., Harmsen, M., Maassen, I. and Wensing, M. (2012) Patient Safety in Midwifery Care for Low-Risk Women: Instrument Development. Journal of Midwifery \& Women's Health, 57, 386-395.

https://doi.org/10.1111/j.1542-2011.2011.00147.x 
[14] White, A., Pichert, J., Blesoe, S., Irwin, C. and Entman, S. (2005) Cause and Effect Analysis of Closed Claims in Obstetrics and Gynecology. Obstetrics and Gynecology, 105, 1031-1038. https://doi.org/10.1097/01.AOG.0000158864.09443.77

[15] Whitehead, D. (2007) An Overview of Research Theory and Process. In: Schneider, W.D., Ed., Nursing \& Midwifery Research. Methods and Appraisal for EvidenceBased Practice, Elliott D. Mosby Publication, Sydney.

[16] Annells, M. and Whitehead, D. (2007) Analyzing Data in Qualitative Research. In: Schneider, W.D., Ed., Nursing \& Midwifery Research. Methods and Appraisal for Evidence-Based Practice, Elliott D. Mosby Publication, Sydney.

[17] World Health Organization (WHO) (2009) The WHO Patient Safety Curriculum Guide for Medical Schools.

http://www.who.int/patientsafety/education/curriculum/download/en/index.html

[18] World Health Organization (WHO) (2011) The WHO Near-Miss Approach. http://www.who.int/reproductivehealth/topics/maternal_perinatal/nmconcept/en/

[19] Morgan, D.L. (1997) Focus Groups as Qualitative Research. Sage Publications, Thousand Oaks. https://doi.org/10.4135/9781412984287

[20] Malterud, K. (2012) Systematic Text Condensation: A Strategy for Qualitative Analysis. Scandinavian Journal of Public Health, 40, 769-805. https://doi.org/10.1177/1403494812465030

[21] World Medical Association Declaration of Helsinki. (2001) Ethical Principles for Medical Research Involving Human Subjects. https://www.ncbi.nlm.nih.gov/pmc/articles/PMC2566407/pdf/11357217.pdf

[22] Raine, R., Cartwright, M., Richens, Y., Muhamed, Z. and Smith, D. (2009) A Qualitative Study of Women's Experiences of Communication in Antenatal Care: Identifying Areas for Action. Maternal and Child Health Journal, 14, 590-599. https://doi.org/10.1007/s10995-009-0489-7

[23] Hunter, B., Berg, M., Lundgren, I., Olafsdottir, O. and Kirkham, M. (2008) Relationships: The Hidden Threads in the Tapestry of Maternity Care. Midwifery, 24, 132-137.

[24] Severinsson, E., Haruna, M., Ronnerhag, M., Holm, A.L., Hansen, B.S. and Berggren, I. (2017) Evidence of Linkages between Patient Safety and Person-Centred Care in the Maternity and Obstetric Context-An Integrative Review. Open Journal of Nursing, 7, 378-398. https://doi.org/10.4236/ojn.2017.73030

[25] Currie, L. and Richens, Y. (2009) Exploring the Perceptions of Midwifery Staff about Safety Culture. British Journal of Midwifery, 17, 783-790. https://doi.org/10.12968/bjom.2009.17.12.45548

[26] Stern, D.N. (1995) The Motherhood Constellation. Karnac Books, London.

[27] Halldorsdottir, S. and Karlsdottir, S.I. (1996) Journeying through Labour and Delivery: Perceptions of Women Who Have Given Birth. Midwifery, 12, 48-61.

[28] Berg, M., Lundgren, I., Hermansson, E. and Wahlberg, V. (1996) Women's Experience of the Encounter with the Midwife during Childbirth. Midwifery, 12, 11-15.

[29] Rørtveit, K., Sætre Hansen, B., Leiknes, I., Joa, I., Testad, I. and Severinsson, E. (2015) Patients' Experiences of Trust in the Patient-Nurse Relationship-A Systematic Review of Qualitative Studies. Open Journal of Nursing, 5, 195-209. https://doi.org/10.4236/ojn.2015.53024

[30] Sammer, C., Lykens, K., Singh, K.P., Mains, D. and Lackan, N.A. (2010) What Is Patient Safety Culture? A Review of the Literature. Journal of Nursing Scholarship, 42, 156-165. https://doi.org/10.1111/j.1547-5069.2009.01330.x 
[31] Ten Hoope-Bender, P., de Bernis, L., Campbell, J., Downe, S., Fauveau, V., Fogstad, H., Homer, C.S.E., Kennedy, H.P., Matthews, Z., McFadden, A., Renfrew, M. and Van Lerberghe, W. (2014) Improvement of Maternal and Newborn Health through Midwifery. The Lancet, 384, 1226-1235.

[32] Berg, M. and Dahlberg, K. (2001) Swedish Midwives' Care of Women Who Are at High Obstetric Risk or Who Have Obstetric Complications. Midwifery, 17, 259-266. https://doi.org/10.1054/midw.2001.0284

[33] Byrom, S. and Downe, S. (2010) "She Sort of Shines": Midwives Accounts of "Good" Midwifery and "Good” Leadership. Midwifery, 26, 126-137.

[34] McCrea, H. (1993) Valuing the Midwife's Role in the Midwife/Client Relationship. Journal of Clinical Nursing, 2, 47-52. https://doi.org/10.1111/j.1365-2702.1993.tb00130.x

[35] Lyckestam Thelin, I., Lundgren, I. and Hermansson, E. (2014) Midwives' Lived Experience of Caring During Childbirth-A Phenomenological Study. Sexual \& Reproductive Healthcare, 5, 113-118.

[36] Malterud, K. (2001) Qualitative Research: Standards, Challenges, and Guidelines. The Lancet, 358, 483-488.

\section{Scientific Research Publishing}

Submit or recommend next manuscript to SCIRP and we will provide best service for you:

Accepting pre-submission inquiries through Email, Facebook, LinkedIn, Twitter, etc. A wide selection of journals (inclusive of 9 subjects, more than 200 journals) Providing 24-hour high-quality service

User-friendly online submission system Fair and swift peer-review system

Efficient typesetting and proofreading procedure

Display of the result of downloads and visits, as well as the number of cited articles Maximum dissemination of your research work

Submit your manuscript at: http://papersubmission.scirp.org/

Or contact ojn@scirp.org 